\title{
Identification and Early Intervention of Bipolar Disorder in Adolescence and Adults
}

\author{
Geeta Rani, Pooja Mehta
}

\begin{abstract}
Bipolar disorder is normally conceptualized as a progressive disorder with the expanding risk of repeat for each new full of the feeling scene and with expanding subjective handicaps over the span of ailment. Clinically, symptomatic limits between bipolar disorder alongside other mental conditions, for example, bipolar disorder are really not clear despite the fact that some mental and pharmacological treatment procedures very impressively. Patients with bipolar disorder are once in a while misdiagnosed as having bipolar disorder, transient psychosis, reaction to a psychoactive substance or stress/change disorder misuse, just as the mean deferral between beginning just as the conclusion is really 5 to 10 yrs. Emotional wellness, just as substance use disorders, as a rule, grow from the get-go in youthful adulthood and youthfulness. Bipolar disorders are really normal, handicapping, repetitive emotional wellness issues of flexible seriousness. The beginning is as a rule in early pre-adulthood or late childhood. Patients with bipolar conditions have more noteworthy paces of different other psychological wellness disorders and by and large wellbeing conditions. Early acknowledgment, just as treatment of bipolar conditions, improve results.
\end{abstract}

Keywords: Bipolar disorder, Patients, Ayurvedic

\section{INTRODUCTION}

Depression is an ailment that influences both the psyche and the body and is the primary wellspring of incapacity, working environment non-appearance, lessened productivity, and high suicide rates. Depression is the most broadly perceived psychiatric disorder by and large practice and around one of each ten patients found in the essential thought settings experience the evil impacts of some kind of depression. Depression is a disorder has reliably been a focal point of the consideration of examiners in India. All through the last 50-60 years, immense amounts of studies have been disseminated from India keeping an eye on various pieces of this customarily basic disorder. The various edges concentrated incorporated the investigation of infection transmission, measurement and psychosocial hazard factor, neurobiology, symptomatology, comorbidity, assessment and determination, the impact of depression, treatment-related issues and repugnance of depression despite the suitability and goodness of various antidepressants. In the present assessment, three social affairs of patients were taken. One social occasion was given Ayurvedic treatment for depression.

Revised Manuscript Received on February 05, 2020.

* Correspondence Author

Geeta Rani*, Research Scholar, Dept. of Psycology, Sri SatyaSai University of Technology \& Medical Sciences, Sehore, Bhopal-Indore Road, Madhya Pradesh, India

Dr. Pooja Mehta, Research Guide, Dept. of Psycology, Sri Satya Sa University of Technology \& Medical Sciences, Sehore, Bhopal Indore Road, Madhya Pradesh, India

(c) The Authors. Published by Blue Eyes Intelligence Engineering and Sciences Publication (BEIESP). This is an open access article under the CC BY-NC-ND license (http://creativecommons.org/licenses/by-nc-nd/4.0/)
The resulting gathering was treated by Cognitive treatment for diminishing their depression and the third assembling was given the joined treatment (Ayurvedic and Cognitive Therapy) for lessening their depression. The examination is directed to see the free effects of Ayurvedic and Cognitive Therapy treatment and their united effect on patients of depression.

Hippocrates portrayed psychological maladjustments into characterizations that included madness, wretchedness (depression), and phrenitis (mind fever). Hippocrates envisioned that depression was achieved by an over the top measure of dim bile in the spleen. He used phlebotomy (to the extent anybody knows the helpful procedure which removed blood from the body), washing, work out, and thinning down to treat depression. Instead of Hippocrates' view, the acclaimed Roman thinker and statesman Cicero battled that depression was achieved by vicious fierceness, dread, and sadness; a psychological explanation rather than a physical one.

The term Major depressive disorder was exhibited by a social affair of US clinicians in the mid-1970s as a segment of recommendation for symptomatic criteria reliant on instances of reactions (called the Research Diagnostic Criteria, developing earlier Feighner Criteria), and was joined into the DSM-III (1980). To keep up consistency the ICD-10 used comparable criteria, with simply minor changes, anyway using the DSM symptomatic edge to stamp a delicate burdensome scene, including higher edge classes for moderate and extraordinary scenes of depression.

\section{Effects of Bipolar Disorder}

Bipolar disorder, generally speaking, suffers until the end of time. Scenes of insanity and depression ordinarily return after some time. Between scenes, various individuals with bipolar disorder are free of side effects, yet a couple of individuals may have holding up side effects. Masters, when in doubt, dissect mental disorders using rules from the Diagnostic and Statistical Manual of Mental Disorders, or DSM. According to the DSM, there are four essential sorts of bipolar disorder:

Bipolar Disorder is mostly portrayed by hyper or mixed scenes that last at any rate seven days, or by hyper manifestations that are not kidding to such a degree, that the individual needs fast restorative facility care. When in doubt, the individual moreover has burdensome scenes, ordinarily suffering at any rate two weeks. The indications of insanity or depression must be a significant change from the person's standard lead.

\section{EPIDEMIOLOGY OF BIPOLAR DISORDER}

Epidemiological assessments have suggested a lifetime inescapability of around $1 \%$ for bipolar sort I in the general people.

Blue Eyes Intelligence Engineering \& Sciences Publication 


\section{Identification and Early Intervention of Bipolar Disorder in Adolescence and Adults}

A colossal cross-sectional purpose of 11 countries found the general lifetime inescapability of bipolar range disorders was $2.4 \%$, with a prevalence of $0.6 \%$ for bipolar sort I and $0.4 \%$ for bipolar kind II. Regardless of the way that disclosures changed crosswise over different countries, this proposed a lower regularity of bipolar sort I and II than past examinations, while the transcendence of the bipolar kind I in the USA was viewed as $1 \%$, insignificantly higher than various countries. It is foggy whether differentiations were a direct result of progressively stringent analytic criteria used in this assessment, or certified differences in paces of bipolar crosswise over countries and ethnic social affairs. In one of the relatively few epidemiological assessments in England, the progressing Adult Psychiatric Morbidity Survey 2014 found lifetime regularity of likely bipolar was $2 \%$. The estimation methodology suggests this was a decry, yet the examination didn't perceive bipolar subtypes. A continuous meta-assessment of 25 assessments found a pooled lifetime ordinariness of $1.06 \%$ and $1.57 \%$ for the bipolar kind I and II, independently, regardless of the way that most of the included assessments were from North or South America. Regardless, a tantamount inescapability has been found in the UK, Germany, and Italy, and a lifetime power between 0.1-1.83percent was found in a systematic review of concentrates from African countries.

\section{MATERIALS AND METHODS}

An imminent accomplice study was led in a tertiary consideration unit in TamilNadu, India. All recently analyzed bipolar disorder patients according to diagnostic and factual manual criteria or recently analyzed bipolar disorder patients yet not on treatment and who are willing to take an interest in the investigation were selected. The patients were pursued for 3 months from the day of enrollment. Patients who are not ready to go for treatment, without clear treatment result as remission or no remission and patients who lost the follow-up were prohibited from the investigation. Patient demography, age at bipolar disorder was analyzed, age at treatment was begun, and social propensities, signs and side effects, therapeutic and psychiatric comorbidities, treatment paten, and consistence to treatment were recorded in a predesigned case record structure.
The HAM-D and YMRS scores were utilized to quantify the seriousness of manic episodes and discouragement, separately, in the study population, at benchmark, and finally development. HAM-D and YMRS were surveyed by master therapists within the sight of the investigator. In light of the adjustments in HAM-D and YMRS scores from standard to the last development, the patients were ordered into abatement and no reduction.

\section{Statistical analyses}

Ostensible information was depicted and communicated in recurrence and percentage. Parametric information was communicated as the mean \pm standard deviation (SD). Comparison of YMRS/HAM-D scores at benchmark and last follow-up was finished utilizing the combined t-test. Different strategic regression was utilized to distinguish chance variables related with no reduction in bipolar disorder patients and figuring of odds ratio (OR). In various calculated regression, factors were chosen dependent on distributed writing and clinical importance as made a decision by master clinicians. Components having not exactly a satisfactory number of occasions $(<10)$ per autonomous variable were excluded from the numerous calculated relapse investigation. $\mathrm{P}<0.05$ was considered factually critical for all investigations. Information section and factual investigation were finished utilizing IIBM SPSS form 20.0 .

\section{RESULTS}

\section{Characteristics of Study population}

During the study time frame, 111 respondents were tried out the investigation based consideration criteria. Quiet demography, age at beginning, treatment result, and different subtleties are outlined in Table 1 . The average age of the examination population was $37.6 \pm 14.1$ years (mean $\pm \mathrm{SD})$, and $56.2 \%(\mathrm{n}=68)$ of the patients were female. Early-beginning bipolar disorder was seen in 14.9\%, (n = 17) and the mean age at early-beginning bipolar sickness was $15.7 \pm 2.4$ (mean \pm SD) years. Treatment delay was seen in $21.5 \%(n=26)$ of patients. Toward the finish of the subsequent period, 33.9\% $(\mathrm{n}=31)$ had abatement and $66.1 \%(n=80)$ had no reduction.

\section{Measures Outcome}

Table 1: Clinical characteristics, demography and outcome of bipolar patients

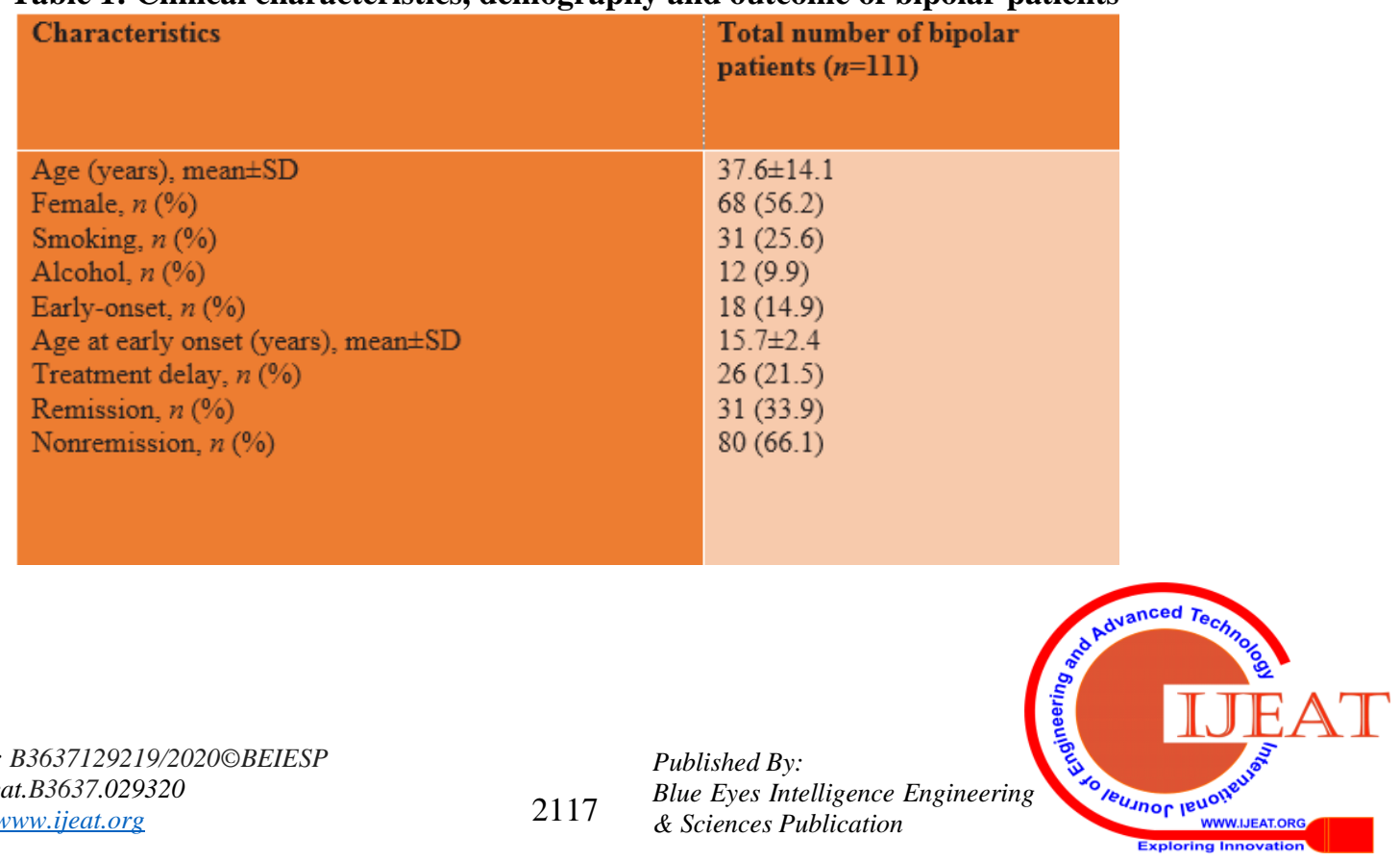


Subtypes of bipolar disorder dependent on explicit state of mind scenes are abridged in Table 2, greater part of the patients $(72.7 \%, \mathrm{n}=78)$ were determined to have Bipolar
I disorder, trailed by Bipolar II disorder (8.2\%, $\mathrm{n}=10)$, cyclothymic disorder $(0.8 \%, \mathrm{n}=1)$, and blended highlights

Table 2: Bipolar Disorder Types

\begin{tabular}{l|l}
\multicolumn{1}{c|}{ Types } & \multicolumn{1}{c|}{ Frequency (\%) } \\
\hline Bipolar I disorder & \\
Bipolar II disorder & $88(72.7)$ \\
Cyclothymic disorder & $10(8.2)$ \\
Mixed features & $1(0.8)$ \\
& $12(18.1)$
\end{tabular}

The result of numerous strategic regression is outlined in Table 3. Twelve factors were examined to distinguish the conceivable relationship with nonremission in the examination population. Early-beginning (OR: 9.77; conviction breaks [CI]: 1.11-86.01), treatment delay (OR: 6.48; CI: 1.27-32.92) treatment revolution (OR: 4.64; CI: 1.37-15.64), and single living (OR: 4.26; CI: 1.56-11.66) were autonomously connected with nonremission in bipolar disorder patients. Different factors, in particular, low salary, melancholy, male sex, hypothyroidism, hypertension, and stoutness likewise had $\mathrm{OR}>1$; be that as it may, they were not measurably noteworthy. Smoking and liquor abuse indicated support abatement yet again results were measurably nonsignificant.

\begin{tabular}{|l|c|c|c|c|c|}
\hline Risk factor & Nonremission, $n$ (\%) & Remission, $n(\%)$ & OR & $95 \%$ CI & $P$ \\
\hline Early onset & $17(94.4)$ & $1(5.6)$ & 9.77 & $1.11-86.01$ & $0.040^{*}$ \\
Treatment delay & $23(88.5)$ & $3(11.5)$ & 6.48 & $1.27-32.92$ & $0.024^{*}$ \\
Treatment noncompliance & $28(84.8)$ & $5(15.2)$ & 4.64 & $1.37-15.64$ & $0.013^{*}$ \\
Low in-come (<Rs. 5000/month) & $48(71.6)$ & $19(28.4)$ & 1.77 & $0.67-4.68$ & 0.253 \\
Depression & $10(76.9)$ & $3(23.1)$ & 1.84 & $0.33-10.26$ & 0.487 \\
Single living & $45(83.3)$ & $9(16.7)$ & 4.26 & $1.56-11.66$ & $0.005 *$ \\
Male sex & $37(69.8)$ & $16(30.2)$ & 2.36 & $0.73-7.64$ & 0.153 \\
Smoking & $21(67.7)$ & $10(32.3)$ & 0.50 & $0.12-2.19$ & 0.360 \\
Alcohol dependence & $8(66.7)$ & $4(33.3)$ & 0.55 & $0.89-3.47$ & 0.434 \\
Hypothyroidism & $13(76.5)$ & $4(23.5)$ & 1.86 & $0.39-8.86$ & 0.865 \\
Hypertension & $12(70.6)$ & $5(29.4)$ & 1.14 & $0.26-4.91$ & 0.732 \\
Obesity & $9(81.8)$ & $2(18.2)$ & 1.41 & $0.20-10.15$ & 0.962 \\
\hline
\end{tabular}

\section{DISCUSSION}

In this work, 111 bipolar disorder patients were pursued for 3 months from the day of enlistment into the investigation. According to as far as anyone is concerned and writing search, it is the principal study endeavored to recognize the elements prompting nonremission in bipolar disorder patients. The mean age of our investigation population was $37.6 \pm 14.1$ years with female transcendence; $(56.2 \%)$ these perceptions were like the outcomes distributed in an examination led by Perry et al., in that review, the mean age was $43 \pm 15$ years with female patients being $68 \%$. The frequency of bipolar disorder is more in female sexual orientation might be because of their way of life or physiological impacts. An investigation directed by Leibenluft indicated that ladies are increasingly inclined to experiencing bipolar disorder when contrasted with men.

In our investigation population, $14.9 \%$ had the earlybeginning bipolar disorder and mean age at early beginning was $15.7 \pm 2.4$. Early-beginning bipolar disorder is generally normal, in an examination directed by Post et al. half of the patient had the early-beginning illness. As indicated by the American Psychiatric Association and as indicated by Wells et al., the average age of the beginning of the principal hyper scene is around 21 years, our outcomes likewise demonstrated a comparative example. As per an investigation directed by McGlashan, it indicated that with the death of immaturity, the disorder turns out to be less entering as for harmfulness. Alternately, late-creating insanity or late beginning of ailment, regardless of whether it is mellow, perhaps crushing to somebody with built up unbending, guarded styles and less versatile adaptability. Treatment delay and suggestions: According to Post et al., treatment delay happens when the patient beginnings his/her medicine a lot after the disorder is analyzed. This can make opposition medications and positive results with the treatment would be influenced.

\section{CONCLUSION}

It is realized that the result of bipolar disorder treatment is profoundly factor and a few patients and ecological related elements may influence the result. 
The recognized components might be utilized as a clinical choice supporting device and tending to these elements in the early period of treatment may lessen the odds of nonremission in bipolar disorder patients and improve their personal satisfaction.

\section{REFERENCES}

1. André F. Carvalho, Iria Grande, Eduard Vieta, Estela Salagre, (2018) "Early Intervention in Bipolar Disorder" The American Journal of Psychiatry, 24 Jan 2018https://doi.org/10.1176/appi.ajp.2017.17090972

2. Anthony J. Levitt, Ayal Schaffer, Carolyn S. Dewa, Paul Kurdyak, (2010) "Bipolar disorder among adolescents and young adults: Results from an epidemiological sample", Journal of Affective Disorders, Volume 125, Issues 1-3,2010, Pages 350-354, ISSN 0165-0327

3. Duffy A. (2009). The early course of bipolar disorder in youth at familial risk. Journal of the Canadian Academy of Child and Adolescent Psychiatry $=$ Journal de l'Academie canadienne de psychiatrie de l'enfant et de l'adolescent, 18(3), 200-205.

4. Duffy, A. Curr Treat Options Psych (2014) 1: 37. https://doi.org/10.1007/s40501-013-0006-X

5. Falkenberg, I., \& Howes, O. D. \& (2011). Early detection and intervention in bipolar affective disorder: targeting the development of the disorder. Current psychiatry reports, 13(6), 493-499. doi:10.1007/s11920-011-0229-8

6. Fu-I L. (2004). Transtorno afetivo bipolar na infância e na adolescência [Bipolar disorder in childhood and adolescence]. Revista brasileira de psiquiatria (Sao Paulo, Brazil : 1999), 26 Suppl 3(Suppl 3), 22-26.

7. Goldstein BI. Recent Progress in Understanding Pediatric Bipolar Disorder. Arch Pediatr Adolesc Med. 2012;166(4):362-371. doi:10.1001/archpediatrics.2011.832

8. Henter, I. D., Manji, H. K., Salvadore, G., Zarate, C. A., \& Drevets, W. C., (2008). Early intervention in bipolar disorder, part I: clinical and imaging findings. Early intervention in psychiatry, 2(3), 122-135. doi:10.1111/j.1751-7893.2008.00071.x

9. Jann M. W. (2014). Diagnosis and treatment of bipolar disorders in adults: a review of the evidence on pharmacologic treatments. American health \& drug benefits, 7(9), 489-499.

10. Marwaha, S., \& Rowland, T. A. (2018). Epidemiology and risk factors for bipolar disorder. Therapeutic advances in psychopharmacology, 8(9), 251-269. doi:10.1177/2045125318769235

11. Shen Y. C. (2018). Treatment of acute bipolar depression. Ci ji yi xue za zhi $=$ Tzu-chi medical journal, 30(3), 141-147. doi:10.4103/tcmj.tcmj_71_18

12. Townsend, L. D., Demeter, C. A., \& Findling, R. L., Wilson, M. (2008). Current research in child and adolescent bipolar disorder. Dialogues in clinical neuroscience, 10(2), 215-228

\section{AUTHORS PROFILE}

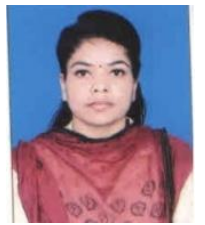

Geeta Rani, Research Scholar, Dept. of Psycology, Sri SatyaSai University of Technology \& Medical Sciences, Sehore, Bhopal-Indore Road, Madhya Pradesh, India

Dr. Pooja Mehta, Research Guide, Dept. of Psycology, Sri Satya Sai University of Technology \& Medical Sciences, Sehore, Bhopal Indore Road, Madhya Pradesh, India 